\title{
Morusin inhibits the growth of human colorectal cancer HCT116-derived sphere-forming cells via the inactivation of Akt pathway
}

\author{
YUQI ZHOU $^{1}$, XIANGYONG $\mathrm{LI}^{1}$ and MIN YE ${ }^{2}$ \\ ${ }^{1}$ Department of Hematology and Oncology, 904 Hospital of PLA Joint Logistic Support Force, Wuxi, Jiangsu 214000; \\ ${ }^{2}$ Department of Traditional Chinese Medicine, Changzheng Hospital, Second Military Medical University, \\ Shanghai 200003, P.R. China
}

Received April 14, 2020; Accepted November 5, 2020

DOI: $10.3892 / \mathrm{ijmm} .2021 .4884$

\begin{abstract}
The existence of colorectal cancer stem-like cells (CSC) is responsible for the failure of current treatments against colorectal cancer. Therefore, novel therapies need be developed to target CSCs. Some natural agents, including morusin have been proposed as possible candidates for this purpose. Morusin has been shown to exert antitumor effects. In the present study, it is demonstrated that morusin exerts antitumor effects on colorectal CSCs (CCSCs). The viability of human CCSCs was enhanced when the CCSCs formed spheroids in a serum-free and non-adhesive floating culture system. HCT116 sphere cells exhibited an increased proliferative capacity and a higher expression of stemness markers [octamer-binding transcription factor 4 (Oct4), Sox 2 and Nanog]. Morusin inhibited the development of cancer spheroids and suppressed the growth of sphere cells via the induction of cell cycle arrest. Similarly, morusin decreased the expression levels of the stemness markers, Nanog and Oct4. The data partially revealed the molecular mechanisms involved: $\beta$-catenin signaling maintains the growth of CSCs and directly modulates the expression of Nanog and Oct 4. Morusin suppressed the activity of $\beta$-catenin signaling via the inactivation of Akt; the executive $\beta$-catenin/TCF4 complex and the downstream targets, c-Myc, survivin and cyclin D1, were also downregulated. Moreover, the morusin-induced inactivation of Akt also increased the expression of p21Cip1/WAF1 and p27Kip, which can block the cell cycle by interacting with cyclin-dependent kinase (CDK) complexes. On the whole, the present study demonstrates that morusin inhibited the growth
\end{abstract}

Correspondence to: Dr Min Ye, Department of Traditional Chinese Medicine, Changzheng Hospital, Second Military Medical University, 415 Fengyang Road, Shanghai 200003, P.R. China E-mail: 13564643706@163.com

Key words: morusin, cancer stem-like cell, cancer sphere cells, Akt, $\beta$-catenin of colorectal cancer sphere cells, which were enriched with CCSCs via the inactivation of the Akt pathway.

\section{Introduction}

Colorectal cancer represented almost $10 \%$ of the global cancer incidence burden in 2012, causing a mortality rate of 694,000 per year worldwide (1). Despite recent advances in medicine, approximately $50 \%$ of patients with colorectal cancer exhibit tumor recurrence (2), and the overall mortality rate associated with the disease is approximately $40 \%$ (3). Colorectal cancer stem-like cells (CCSCs) are considered to be one of the primary causes of tumor recurrence.

Cancer stem-like cells (CSCs) are defined as "cells within a tumor that possess the capacity for self-renewal and that can cause the heterogeneous lineages of cancer cells that constitute the tumor' (4). At present, CSCs have been proven to exist in a variety of solid tumors, including colon cancer (5-7). It is considered that only CSCs can drive tumor initiation, proliferation and spreading (8). In addition, CSCs are not affected by chemotherapy or radiation (9). CSCs that survive chemoradiotherapy will initiate and maintain the regrowth of the tumor. A number of currently used protocols for cancer therapy are now understood to fail, as marked by the reappearance of disease, due to the inability to eradicate CSCs. Therefore, the requirement and the challenge in fighting cancer is to develop novel therapies targeting CSCs. To counteract the challenges, researchers have turned to natural products. Some natural agents, including morusin (10), have been proposed as candidates for the targeting of CSCs alone or in combination with chemoradiotherapy $(11,12)$.

Morusin (2-(2,4-dihydroxyphenyl)-5-hydroxy-8,8-dimethyl-3-(3-methylbut-2-enyl)pyranol[2,3-h]chromen-4-one, $\mathrm{C}_{25} \mathrm{H}_{24} \mathrm{O}_{6}$ ) (NCBI PubChem Compound database, CID:5281671) is a naturally occurring agent isolated from the traditional Chinese medicinal (TCM) herb, Morus alba L. (Sang Bai Pi), which is used as an antiphlogistic, an antipyretic, an expectorant, an antitussive, a diuretic and an antidiabetic medication $(13,14)$. Researchers have demonstrated that morusin exerts antitumor effects in several types of neoplasms, including hepatocellular carcinoma $(15,16)$, 
gastric cancer (16), cervical cancer (10) and neuroblastoma (17). To the best of our knowledge, the last and only study on the antitumor activity of morusin against colorectal cancer was published in 2008 (14), in which it was reported that morusin induced the nuclear factor $(\mathrm{NF})-\kappa \mathrm{B}-$ mediated apoptosis of HT-29 colorectal cancer cells. Based on previous research, it was hypothesized that morusin may exert antitumor effects on CCSCs. To confirm this hypothesis, in the present study, the effects of morusin treatment on CCSCs were examined and the potential underlying mechanisms were investigated.

\section{Materials and methods}

Drugs. Morusin (purity 99\%) was purchased from the Shanghai Research Center of Traditional Chinese Medicine Standardization. Morusin was dissolved in dimethyl sulfoxide (DMSO) to a concentration of $4,800 \mu \mathrm{M}$. The stock solution was stored at $-20^{\circ} \mathrm{C}$ and diluted in the medium before the experiment. The final DMSO concentration did not exceed $1 \%$ throughout the study.

Reagents and antibodies. McCoy's 5A medium, Dulbecco's modified Eagle's medium (DMEM)/F12 medium, fetal bovine serum and B27 supplement (50X) were obtained from Gibco; Thermo Fisher Scientific, Inc. Penicillin G, streptomycin and Heparin $\mathrm{Na}$ salt were purchased from Sigma-Aldrich; Merck KGaA. Epidermal growth factor (EGF) and basic fibroblast growth factor (bFGF) were purchased from PeproTech, Inc. The primary antibodies [octamer-binding transcription factor 4 (Oct4) (cat. no. sc-5279), Sox 2 (cat. no. sc-365823) and Nanog (cat. no. sc-293121)] used for immunofluoresence assay were purchased from Santa Cruz Biotechnology, Inc. The primary antibodies used for western blot analysis were purchased from the following companies: Cell Signaling Technology, Inc. [Oct4 (cat. no. 2750), Sox 2 (cat. no. 3579), Nanog (cat. no. 4903), $\beta$-catenin (cat. no. 8480), transcription factor 4 (TCF4) (cat. no. 2569), c-Myc (cat. no. 18583) and survivin (cat. no. 2808)], Elabscience $^{\circledR}$ [Akt (cat. no. E-AB-30471), phospho-Akt-473 (cat. no. E-AB-21135), glycogen synthase kinase (GSK)-3 $\beta$ (cat. no. E-AB-20885) ], American Research Products, Inc. [CDK2 (cat. no. A2439), cyclin D1 (cat. no. 10-M1033) and p21Cip1/WAF1 (cat. no. 24-1026-MSM3)] and ProteinTech Group, Inc. [(p27Kip1 (cat. no. 25614-1-AP), cyclin A2 (cat. no. 27242-1-AP), GAPDH (cat. no. 60004-1-Ig) and $\beta$-actin (cat. no. 20536-1-AP)].

Cells and cell culture. The HCT116 human colorectal cancer cell line was purchased from the Shanghai Type Culture Collection of the Chinese Academy of Sciences. HCT116 cells were cultured in McCoy's 5A medium supplemented with $10 \%$ fetal bovine serum, $100 \mathrm{U} / \mathrm{ml}$ penicillin $\mathrm{G}$ and $100 \mu \mathrm{g} / \mathrm{ml}$ streptomycin. The cells were cultured in a humidified $5 \% \mathrm{CO}_{2}$ atmosphere at $37^{\circ} \mathrm{C}$. The human fetal colon (FHC) cells (a gift from Dr Hu of Shanghai Funeng Biotechnology Co., Ltd.) were cultured in a 1:1 mixture of Ham's F12 and DMEM (Corning, Inc.) containing HEPES (25 mM), cholera toxin (10 ng/ml; Sigma-Aldrich; Merck KGaA), insulin $(5 \mathrm{lg} / \mathrm{ml})$, transferrin $(5 \mathrm{lg} / \mathrm{ml})$ and hydrocortisone
(100 ng/ml; Sigma-Aldrich; Merck KGaA), supplemented with $10 \%$ fetal bovine serum (FBS) (Invitrogen; Thermo Fisher Scientific, Inc.).

Spheroid formation. Spheroid formation was enriched using a serum-free and non-adhesive floating culture system. Prior to spheroid formation, viable cells were counted by trypan blue staining and seeded in 24-well ultra-low attachment plates (Corning Inc.) at a density of 2,000 cells per well in $500 \mu \mathrm{l}$ $1 \mathrm{X}$ serum-free medium (SFM) (DMEM/F12 medium supplemented with $20 \mathrm{ng} / \mathrm{ml}$ EGF, $20 \mathrm{ng} / \mathrm{ml} \mathrm{bFGF}, 4 \mu \mathrm{g} / \mathrm{ml}$ Heparin Na salt and 1X B27 supplement) for 8 days; subsequently, $50 \mu 1$ of 10X SFM medium per well was added on days 3, 5 and 7 . Tumor spheroids were dissociated, digested and harvested on day 8 , and the viable cells were stained with $0.4 \%$ trypan blue staining solution for $5 \mathrm{~min}$ at room temperature. Single-sphere cell suspensions were cultured in McCoy's 5A medium, then treated with the morusin $(0,9.1,18.2$ and $36.4 \mu \mathrm{M})$. Spheroids were observed under an inverted fluorescent microscope (Olympus Corporation).

Cell proliferation assay/Cell Counting Kit (CCK)-8 assay. The proliferation of the HCT116 cells and FHC cells was measured using a CCK-8 assay (Dojindo Molecular Technologies, Inc.). There were 3 general groups: The blank group (McCoy's 5A medium without cells or drugs), the control group (cells were cultured in McCoy's 5A medium without the drug) and the experimental groups (cells were exposed to 2.5, 5, $10,15,20,25$, or $50 \mu \mathrm{M}$ morusin for $72 \mathrm{~h}$, or to $9.1,18.2$ or $36.4 \mu \mathrm{M}$ morusin for 24,48 or $72 \mathrm{~h}$ ). Following treatment, the culture medium was discarded and $100 \mu \mathrm{l}$ of fresh medium including $10 \mu \mathrm{l}$ of CCK-8 was added to each well. Following $4 \mathrm{~h}$ of incubation in a humidified $5 \% \mathrm{CO}_{2}$ atmosphere at $37^{\circ} \mathrm{C}$, the absorbance was measured at $450 \mathrm{~nm}$ using a Multiskan Spectrum Microplate Reader (Bio-Rad Laboratories, Inc.). The experiments were performed in triplicate. The percentage inhibitory rate (IR\%) of the treated cells was calculated using the following formula: IR\%=1-[(EXP group OD450 nm-blank group OD450 nm)/(CTRL group OD450 nm-Blank group OD450 nm)] x100\%.

5-Ethynyl-2'-deoxyuridine (EdU) assay. Cells were seeded in Millicell EZ 8-well glass slides (EMD Millipore) at a density of $1 \times 10^{4}$ cells/well, and the cells were exposed to $9.1,18.2$ or $36.4 \mu \mathrm{M}$ Morusin for $24 \mathrm{~h}$. Following treatment, the culture medium was discarded, and an EdU incorporation assay was performed using a Cell-Light ${ }^{\mathrm{TM}}$ EdU Apollo ${ }^{\circledR} 567$ In Vitro Imaging kit (Ribobio Co.) according to the manufacturer's instructions. The stained cells were observed under a fluorescence microscope (Olympus Corporation), images were captured and analyzed using ImageJ software (https://imagej. nih.gov/ij/download.html).

Immunofluorescence assay. Cells were seeded in Millicell EZ 8-well glass slides (EMD Millipore) at a density of $1 \times 10^{4}$ cells/well, washed with phosphate-buffered saline (PBS), fixed and permeated using a BD Cytofix/Cytoperm ${ }^{\mathrm{TM}}$ kit (BD Biosciences). The cells were then incubated with Oct4, Sox 2 and Nanog antibodies at a dilution of 1:50 in 1\% bovine serum albumin (BSA)-PBS at $4^{\circ} \mathrm{C}$ overnight followed by 
Table I. Primer sequences used for RT-PCR.

\begin{tabular}{llr}
\hline Gene & \multicolumn{1}{c}{ Primer sequences (5'-3') } & Product length (bp) \\
\hline Oct4 & F: GGG TGG AGA GCA ACT CCG A & 150 \\
& R: GCT TGG CAA ATT GCT CGA G & 150 \\
Fox2 & F: GTT CTA GTG GTA CGG TAG GAG CTT TG & \\
& R: TTT GAT TGC CAT GTT TAT CTC GAT \\
Nanog & F: CCA GCT GTG TGT ACT CAA TGA ATT T & 150 \\
& R: TTC TGC CAC CTC TTA GAT TTC ATT C & 150 \\
& F: TCG GAG GTT CGA AGA CGA TC &
\end{tabular}

F, forward; R, reverse; Oct4, octamer-binding transcription factor 4.

incubation with the secondary antibody [goat anti-mouse IgG H\&L (Alexa Fluor ${ }^{\circledR}$ 647) (Abcam, 1:200, cat. no. ab150115) and donkey anti-goat IgG H\&L $\left(\mathrm{Cy}^{\circledR}\right)$ (Abcam, 1:400, cat. no. ab97117)] in 1\% BSA-PBS at room temperature in the dark for $1 \mathrm{~h}$. The cells were then washed with PBS and stained with $10 \mu \mathrm{g} / \mathrm{ml}$ Hoechst 33342 (Abcam, cat. no. ab228551) at room temperature in the dark for $5 \mathrm{~min}$. The stained cells were observed under a fluorescence microscope, and images were captured and analyzed using ImageJ software.

Detection of cell cycle distribution by flow cytometry. Following treatment with $9.1,18.2$ or $36.4 \mu \mathrm{M}$ morusin for $24 \mathrm{~h}$, the cells were harvested, washed with $4^{\circ} \mathrm{C} \mathrm{PBS}$ and stored in cold $70 \%$ ethanol at $-20^{\circ} \mathrm{C}$ overnight. The cells were centrifuged $(200 \mathrm{x} \mathrm{g})$ for $4 \mathrm{~min}$ at room temperature, then stained with propidium iodide (PI) treated with RNase A $(100 \mathrm{U} / \mathrm{ml})$ and detected by flow cytometry (FACScan; BD Biosciences) for cell cycle analysis.

Detection of apoptotic cells by flow cytometry. Cell apoptosis was detected using an Annexin V-Fluorescein Isothiocyanate (FITC) Apoptosis Detection kit I (BD Biosciences) according to the following protocol: The cells were seeded in 6-well plates at a density of $2 \times 10^{5}$ cells/well and exposed to $9.1,18.2$ or $36.4 \mu \mathrm{M}$ morusin for $24 \mathrm{~h}$. The cells were digested, incubated with FITC-Annexin buffer at room temperature for $10 \mathrm{~min}$, stained with PI and detected by flow cytometry (FACScan; BD Biosciences).

Reverse transcription-polymerase chain reaction (RT-PCR). Total RNA was extracted from the cells using the RNeasy Micro kit (Qiagen $\mathrm{GmbH})$. Total RNA $(0.5 \mu \mathrm{g})$ was used as a template to prepare cDNA (Reverse Transcription System, Promega Corporation; cat. no. A3500) according to the manufacturers' instructions. The amplification conditions were as follows: Stage 1 (holding $95^{\circ} \mathrm{C}$ for $10 \mathrm{~min}$ ); stage 2 (40 cycles of denaturing at $95^{\circ} \mathrm{C}$ for $15 \mathrm{sec}$, annealing at $60^{\circ} \mathrm{C}$ for $45 \mathrm{sec}$ and extending at $72^{\circ} \mathrm{C}$ for $30 \mathrm{sec}$ ); stage 3 (extension at $72^{\circ} \mathrm{C}$ for $7 \mathrm{~min}$ ). The primer sequences are listed in Table I. The housekeeping gene GAPDH was used as an internal reference to normalize the results. All experiments were performed in triplicate. Finally, the $2^{-\Delta \Delta \mathrm{Cq}}$ method was performed to calculate the relative expression (18).
Semi-quantitative RT-PCR. Similarly, total RNA was extracted from the cells and the cDNAs were prepared as described above for RT-PCR. Subsequently, $1 \%$ of the cDNA samples were used for GAPDH, Oct4, Sox2, Nanog PCR. Sense primers were ${ }^{32} \mathrm{P}$-radiolabeled with $\mathrm{T} 4$ polynucleotide kinase. The PCR reactions were performed with the following profile: $30 \mathrm{sec}$ denaturation at $94^{\circ} \mathrm{C}, 15 \mathrm{sec}$ annealing, $25 \mathrm{~s}$ extension at $72^{\circ} \mathrm{C}$. An initial denaturation step at $94^{\circ} \mathrm{C}$ for $2.5 \mathrm{~min}$ and a final extension step at $72^{\circ} \mathrm{C}$ for $7 \mathrm{~min}$ were also performed. The PCR products were analyzed by $2 \%$ agarose gel electrophoresis and stained with ethidium bromide.

Western blot analysis. HCT116 sphere cells were seeded in $10-\mathrm{mm}$ dishes at a density of $2 \times 10^{6}$ cells per dish and were exposed to $9.1,18.2$, or $36.4 \mu \mathrm{M}$ morusin for $24 \mathrm{~h}$. Following treatment, the cells were washed with cold PBS at $4^{\circ} \mathrm{C}$, lysed in RIPA lysis buffer including PhosSTOP (Roche Diagnostics) and $1 \mu \mathrm{M}$ PMSF at $4^{\circ} \mathrm{C}$ for $30 \mathrm{~min}$. Cell lysates were homogenized and centrifuged of $14,000 \mathrm{x} \mathrm{g}$ at $4^{\circ} \mathrm{C}$ for $10 \mathrm{~min}$. The protein concentration was detected by Enhanced BCA Protein Assay kit (Beyotime Institute of Biotechnology). Equal amounts of total protein $(40 \mu \mathrm{g})$ were boiled, loaded onto an $8 \%$ SDS-PAGE gel and electrotransferred to polyvinylidene fluoride (PVDF) membranes (EMD Millipore). After blocking with 5\% non-fat milk in Tris-buffered saline (TBST) for $2 \mathrm{~h}$ at room temperature, the membranes were incubated with the primary antibodies at $4^{\circ} \mathrm{C}$ overnight and incubated with 1:4,000 dilutions of secondary antibodies labeled with horseradish peroxidase [rabbit anti-mouse IgG H\&L (HRP), Abcam, cat. no. ab6728)] at room temperature for $1 \mathrm{~h}$. After being washed with TBST 3 times, the target proteins were detected using an Enhanced Chemi Luminescence (ECL) kit (Thermo Fisher Scientific, Inc.). Finally, images were captured by ChemiDoc ${ }^{\mathrm{TM}} \mathrm{XRS}+$ (Bio-Rad Laboratories, Inc.).

Statistical analysis. All data were analyzed using the Statistical Package Social Science (SPSS) 19.0 software and are expressed as the means \pm SD. Statistical analysis was performed among multiple groups by one-way analysis of variance (ANOVA) followed by Tukey's post hoc test. Values of $\mathrm{P}<0.05$ and $\mathrm{P}<0.01$ were considered to indicate statistically significant and highly statistically significant differences, respectively. 


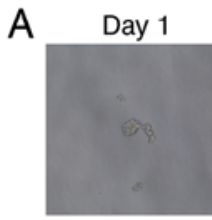

Day 5
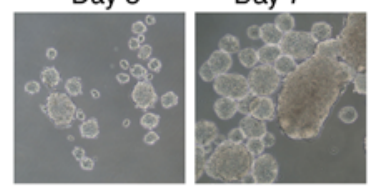

Day 7

Day 3

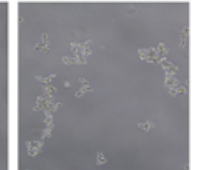

.
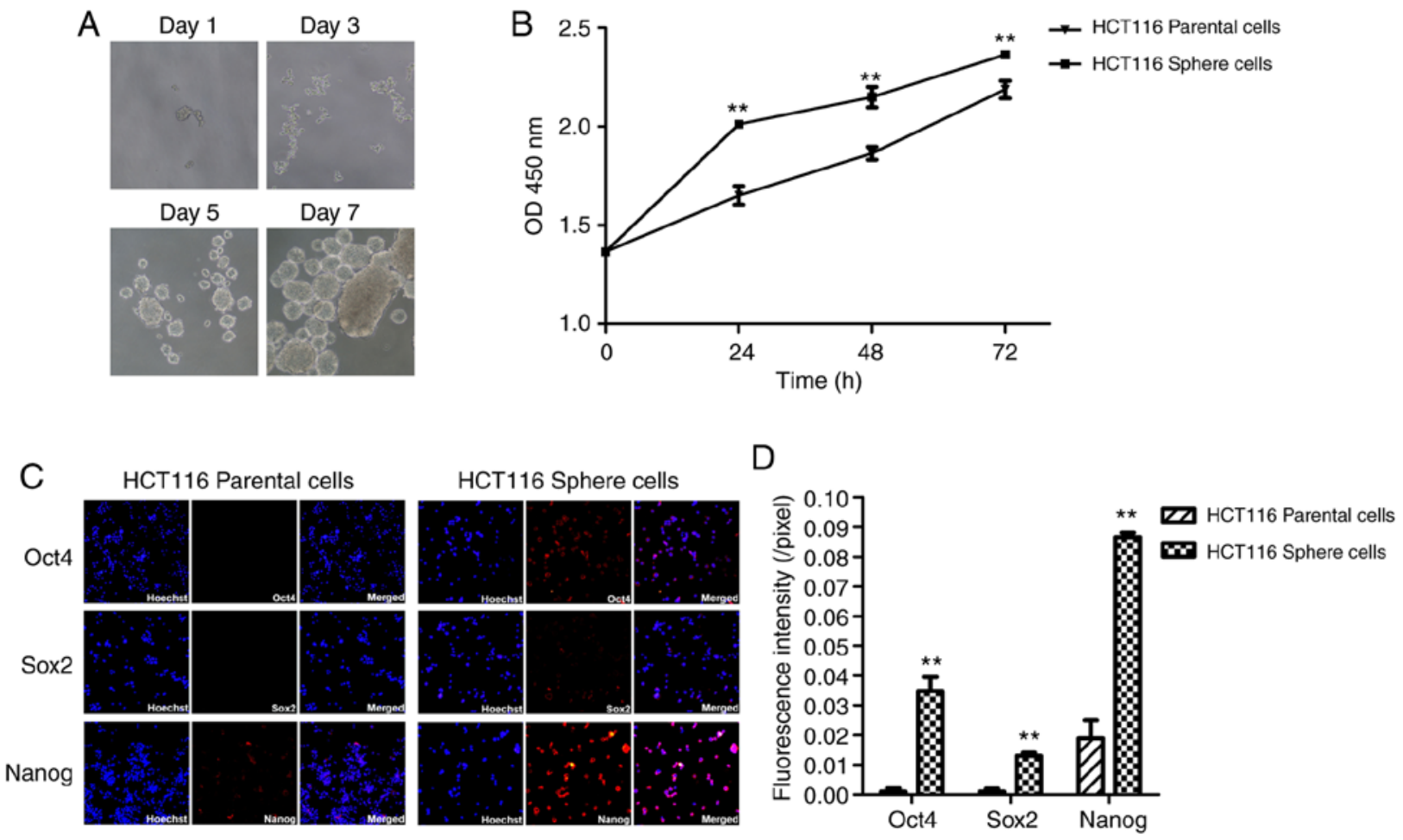

Figure 1. Enrichment and biological characterization of CCSCs. (A) Spheroid-formation state of HCT116 cells over a period of 1-7 days. (B) Cell growth inhibition assay revealed that HCT116 sphere cells had an increased proliferative capacity at 24, 48 and 72 h. (C) The expression of Oct4, Nanog, and Sox 2 in HCT116 parental and sphere cells was assayed by immunofluorescent staining assay (magnification, x200). (D) Fluorescence intensity of Oct4, Nanog and Sox 2 expression in HCT116 parental and sphere cells. All the data are expressed as the means \pm SD of data obtained in 3 parallel experiments; ${ }^{* *}$ P $<0.01$ vs. HCT116 parental cells. CCSCs, colorectal cancer stem cells.

\section{Results}

Enrichment and biological characterization of CCSCs. Spheroid formation was induced in a serum-free and non-adhesive floating culture system (SFM) enriched with CCSCs (19), as it has been demonstrated that sphere cells are enriched with CSCs $(20,21)$. Visible tumor spheroids were observed under an optical microscope on day 3 and were then gradually grown for the following 5 days (Fig. 1A). Following spheroid formation, the number of viable cells in each well increased from 2,000 to $65,500 \pm 18,358$. To evaluate the proliferative capacity of the HCT116 sphere cells, HCT116 parental and sphere cells were seeded in 96-well plates at a density of 5,000 cells per well in McCoy's 5A medium, and CCK-8 assay was performed at 24, 48 and $72 \mathrm{~h}$. The sphere cells exhibited an increased proliferative capacity compared with the parental cells $(\mathrm{P}<0.01$; Fig. 1B). Subsequently, the expression levels of stemness markers (Oct4, Sox 2 and Nanog) was detected by immunofluorescence staining. It was observed that Nanog mRNA and protein expression was detectable in the HCT116 parental cells, whereas Oct4 and Sox 2 expression was undetectable. By contrast, the Oct4, Sox 2 and Nanog expression levels were significantly increased in the HCT116 sphere cells, with a particular increase noted in Nanog mRNA and protein expression (Fig. 1C). As shown in Fig. 1D, the fluorescence intensity of Oct4, Sox 2 and Nanog expression was significantly upregulated in the HCT116 sphere cells (each $\mathrm{P}<0.01$ ). Taken together, the results indicated that there was an upregulation in the expression of stemness-related transcription factors (Oct4, Sox 2 and Nanog) in HCT116 sphere cells.
Inhibitory effects of morusin on the growth of HCT116 sphere cells (results of CCK-8 and EdU assays). The proliferation of HCT116 sphere cells was assessed by CCK- 8 assay. The HCT116 sphere cells were treated with various concentrations of morusin $(2.5,5.0,10.0,15.0,20.0,25.0$ and $50.0 \mu \mathrm{M})$ for $72 \mathrm{~h}$. When the concentration was $\geq 5.0 \mu \mathrm{M}$, morusin significantly inhibited the proliferation of HCT116 sphere cells in a concentration-dependent manner $(\mathrm{P}<0.01)$; an approximately $50 \%$ growth inhibition at $72 \mathrm{~h}$ was achieved at the concentration of $18.2 \mu \mathrm{M}\left(\mathrm{IC}_{50}\right)$ (Fig. 2A). Subsequently, the HCT116 sphere cells were treated with $9.1,18.2$, or $36.4 \mu \mathrm{M}$ morusin for 24,48 and $72 \mathrm{~h}$. Morusin significantly decreased cell viability at each time point $(\mathrm{P}<0.01$; Fig. $2 \mathrm{~B}$ and $\mathrm{C})$. These results indicated that treatment with morusin led to a significant inhibition of cell growth in a concentration- and time-dependent manner.

To further evaluate the proliferative activity of HCT116 sphere cells following treatment with morusin, an EdU incorporation assay was also performed (Fig. 2D). Following treatment with $9.1,18.2$, or $36.4 \mu \mathrm{M}$ morusin for $24 \mathrm{~h}$, cell viability was decreased from $70.65 \pm 5.33$ to $29.54 \pm 3.33,13.23 \pm 1.19$ and $4.12 \pm 1.13 \%$, respectively. There was a significant decrease in EdU incorporation when the cells were incubated with morusin $(\mathrm{P}<0.01$; Fig. 2E), suggesting that morusin significantly inhibited the proliferative activity of the HCT116 sphere cells. In addition, the proliferation of normal FHC cells treated with morusin $(9.1,18.2$ and $36.4 \mu \mathrm{M})$ demonstrated that morusin did not affect normal colonic mucosa cell viability (Fig. 2F).

Morusin inhibits the initiation of colorectal cancer spheroid formation. To determine whether morusin inhibits the 
A
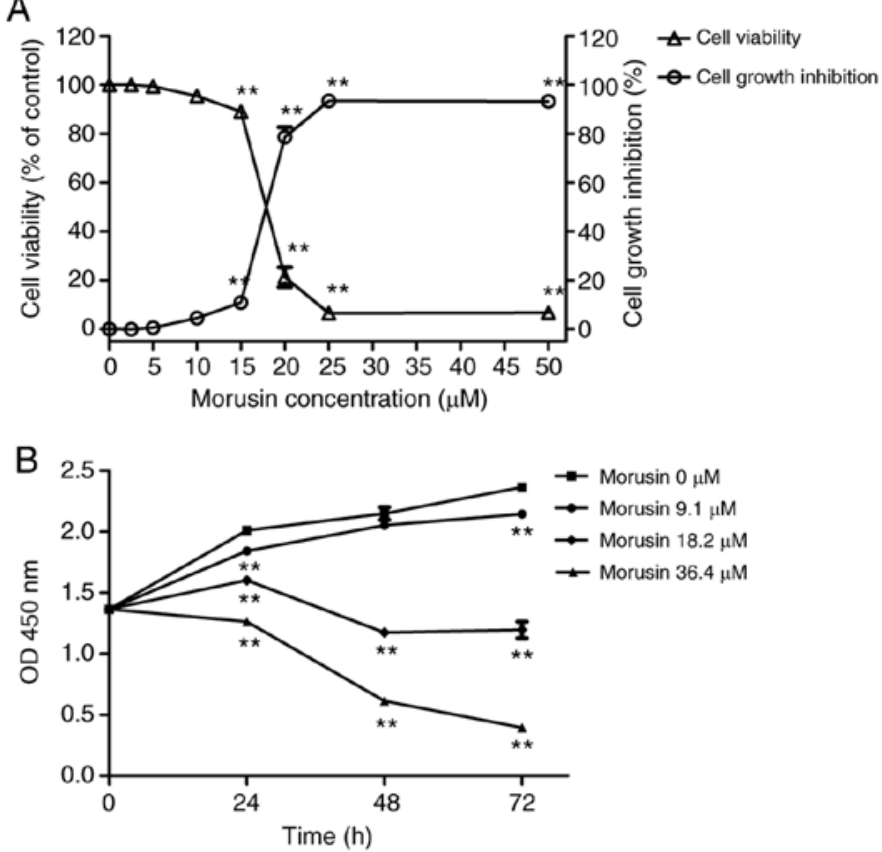

C

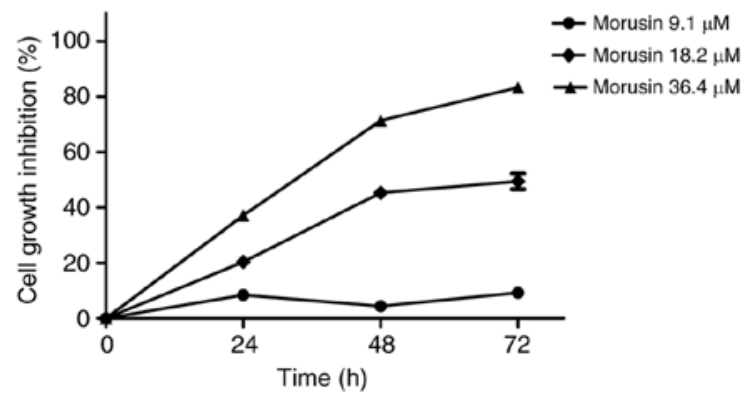

D
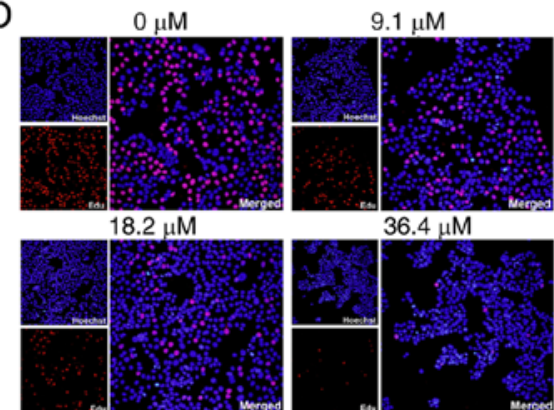

$36.4 \mu \mathrm{M}$

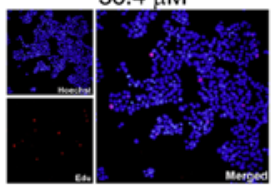

E
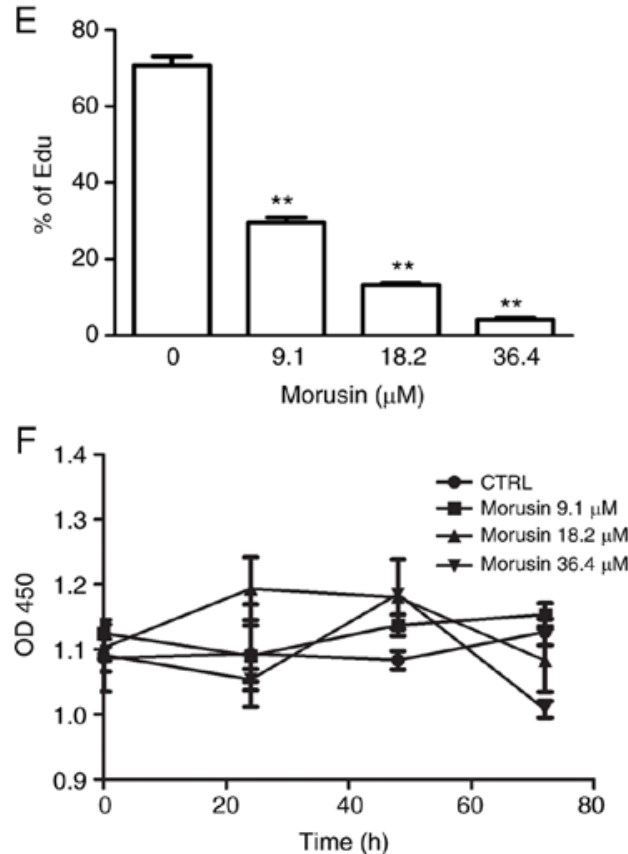

Figure 2. Inhibitory effects of morusin on the growth of HCT116 sphere cells. (A) Results of cell viability and cell growth inhibition assay in HCT116 sphere cells following treatment with increasing concentrations of morusin for $72 \mathrm{~h}$. (B and C) Results of (B) OD450 nm and (C) cell growth inhibition assay in HCT116 sphere cells following treatment with morusin (9.1, 18.2 and $36.4 \mu \mathrm{M})$ for 24, 48 and $72 \mathrm{~h}$. (D) Following treatment with morusin (4.6, 9.1, 18.2 and 36.4 $\mu \mathrm{M})$ for $24 \mathrm{~h}$, the proliferative ability of HCT116 sphere cells was measured by EdU incorporation assay (magnification, x200). (E) The number of positive cells in the EdU incorporation assay was counted. The EdU-positive rate is shown. (F) The proliferation of normal fetal colonic mucosa cells (FHC cells) treated with morusin $(9.1,18.2$ and $36.4 \mu \mathrm{M})$ for 24,48 and $72 \mathrm{~h}$. All data are expressed as the means \pm SD of the data obtained in 3 parallel experiments; ${ }^{* *} \mathrm{P}<0.01 \mathrm{vs}$. control.

initiation of cancer spheroids formation, HCT116 cells were pre-treated with 9.1, 18.2, or $36.4 \mu \mathrm{M}$ morusin for $24 \mathrm{~h}$. The culture medium was then removed and the cells were washed with PBS and collected; viable cells were seeded at a density of 2,000 viable cells per well. Following culture in CSC medium for 7 days, images of each cell group were obtained and the viable cells were counted by trypan blue staining. As shown in Fig. 3A, the HCT116 parental cells that were pre-treated with $9.1 \mu \mathrm{M}$ morusin could only rarely form spheroids; in the higher concentration groups (18.2 and $36.4 \mu \mathrm{M})$, the HCT116 parental cells lost the ability to initiate tumor spheroid formation entirely. Compared with the control group, the number of viable cells in the experimental groups (morusin at 9.1, 18.2 and $36.4 \mu \mathrm{M})$ was significantly decreased $(\mathrm{P}<0.01$; Fig. 3B). These results indicated that the spheroid-forming capacity of the HCT116 cells was suppressed by morusin.

Effect of Morusin on the cell cycle and apoptosis of HCT116 cells. After being incubated with morusin for $24 \mathrm{~h}$, the cell cycle status and apoptosis were detected by flow cytometry. Compared with the control group, morusin (9.1, 18.2 and

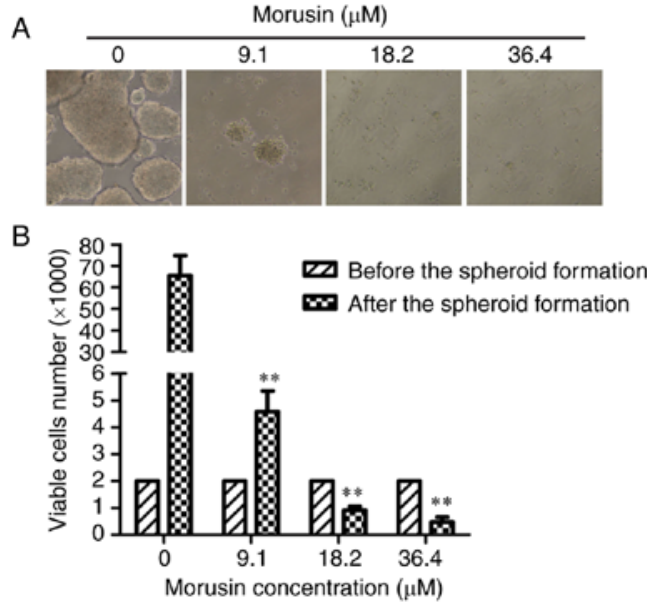

Figure 3. Morusin inhibits the initiation of cancer spheroid-formation. (A) Following pre-treatment with morusin $(4.6,9.1,18.2$ and $36.4 \mu \mathrm{M})$ for $24 \mathrm{~h}$, the surviving viable cells were cultured in SFM at a density of 2,000 cells per well for 7 days; the spheroid-formation state is shown at day 8 . (B) The number of viable cells was counted after harvesting the spheroids; data are expressed as the means \pm SD of the data obtained in 3 parallel experiments; ${ }^{* *} \mathrm{P}<0.01$ vs. control (no treatment). 

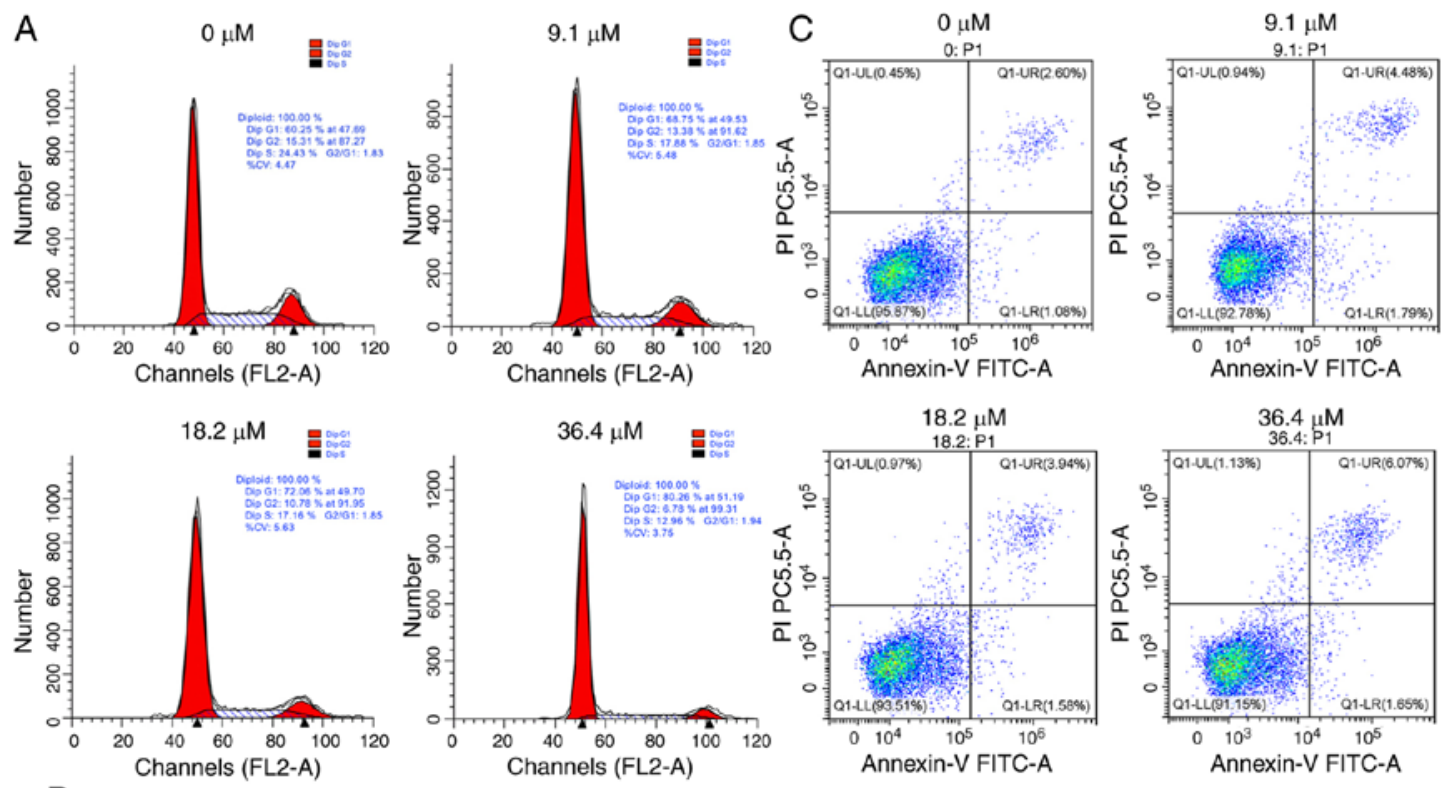

B
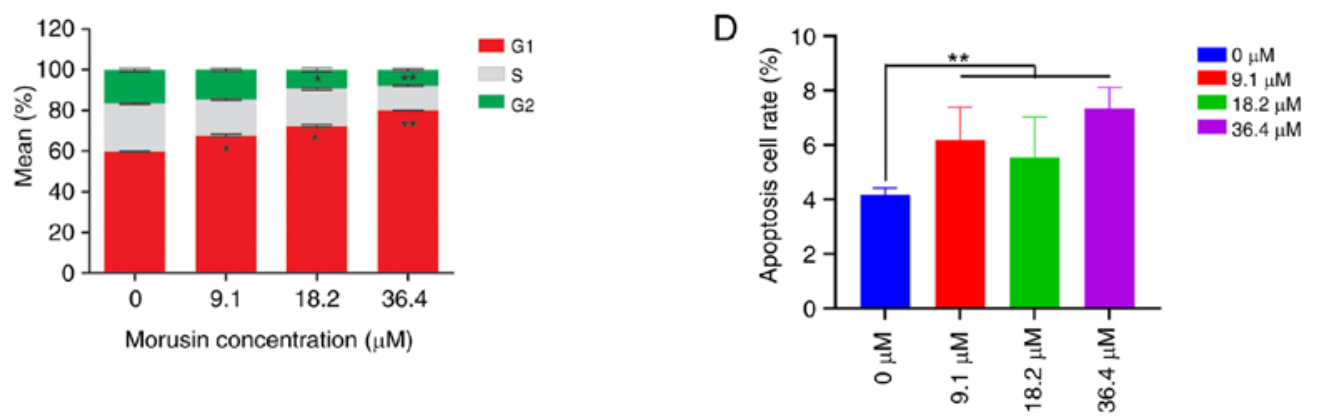

Figure 4. (A and B) Cell cycle status of HCT116 sphere cells treated with morusin (9.1, 18.2 and $36.4 \mu \mathrm{M}$ ) for $24 \mathrm{~h}$. (C and D) Apoptosis of HCT116 sphere cells treated with morusin $(9.1,18.2$ and $36.4 \mu \mathrm{M})$ for $24 \mathrm{~h}$. All data are expressed as the means \pm SD of the data obtained in 3 parallel experiments; ${ }^{*}<0.05$, ${ }^{* *} \mathrm{P}<0.01$ vs. control.

$36.4 \mu \mathrm{M})$ significantly increased the percentage of cells in the $\mathrm{S}$ phase $(\mathrm{P}<0.01)$ and decreased the percentage of cells in the $\mathrm{G} 0 / \mathrm{G} 1$ phase $(\mathrm{P}<0.01)$; the higher concentrations of morusin $(18.2$ and $36.4 \mu \mathrm{M})$ decreased the percentage of cells in the G2/M phase ( $\mathrm{P}<0.05$; Fig. $4 \mathrm{~A}$ and $\mathrm{B})$. These results indicated that morusin induced cell cycle arrest at the $\mathrm{S}$ phase in the HCT116 sphere cells. The percentages of apoptotic cells in each group are shown in Fig. 4C and D. It was found that morusin induced the apoptosis of HCT116 sphere cells in a dose depended manner. The apoptotic rate of the HCT116 sphere cells increased with the increased concentration of morusin.

Effect of Morusin on the expression of stemness markers. The expression levels of stemness markers (Oct4, Sox 2 and Nanog) were detected by RT-PCR and western blot assay. There was a decreasing trend in Nanog mRNA expression following morusin treatment. In addition, the results of western blot analysis further confirmed that morusin inhibited the protein expression of Nanog in a concentration-dependent manner. Furthermore, the Oct 4 protein expression level was decreased in the group treated with the higher concentration of morusin $(36.4 \mu \mathrm{M})$; however, the Sox 2 protein expression level was too low to be detectable (Fig. 5).

Morusin suppresses the activity of the Akt/ $\beta$-catenin pathway. Subsequently, the mechanisms involved in the morusin-induced
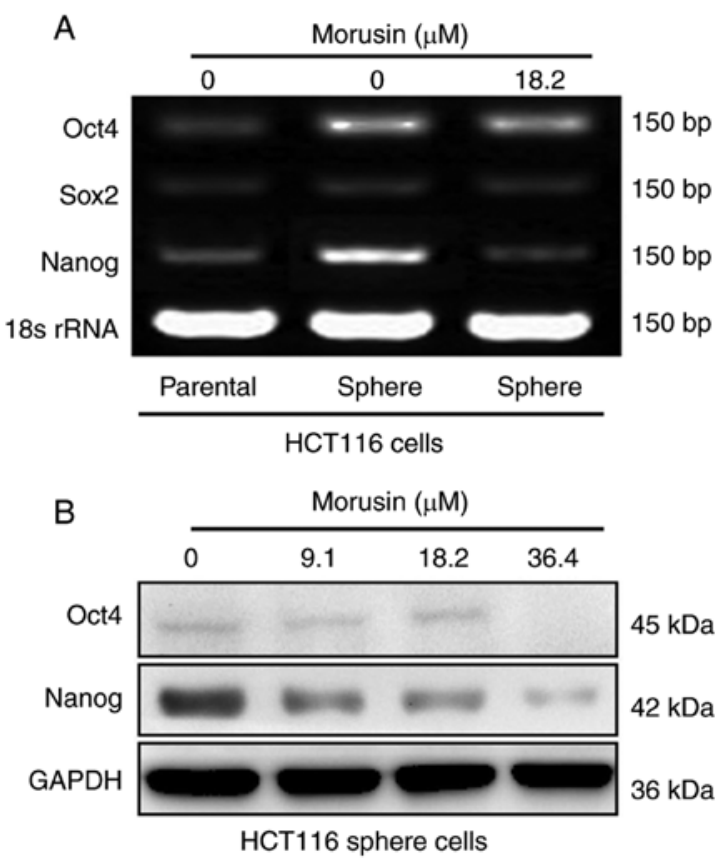

Figure 5. Effect of Morusin on the expression of stemness markers. (A) RT-PCR assays were performed for Oct4, Sox 2 and Nanog mRNA expression in HCT116 parental cells, HCT116 sphere cells and morusin (18.2 $\mu \mathrm{M})$-treated HCT116 sphere cells. (B) Following treatment with morusin (9.1, 18.2 and $36.4 \mu \mathrm{M}$ ) for $24 \mathrm{~h}$, western blot analysis was performed for Oct 4 and Nanog protein expression in HCT116 sphere cells. 

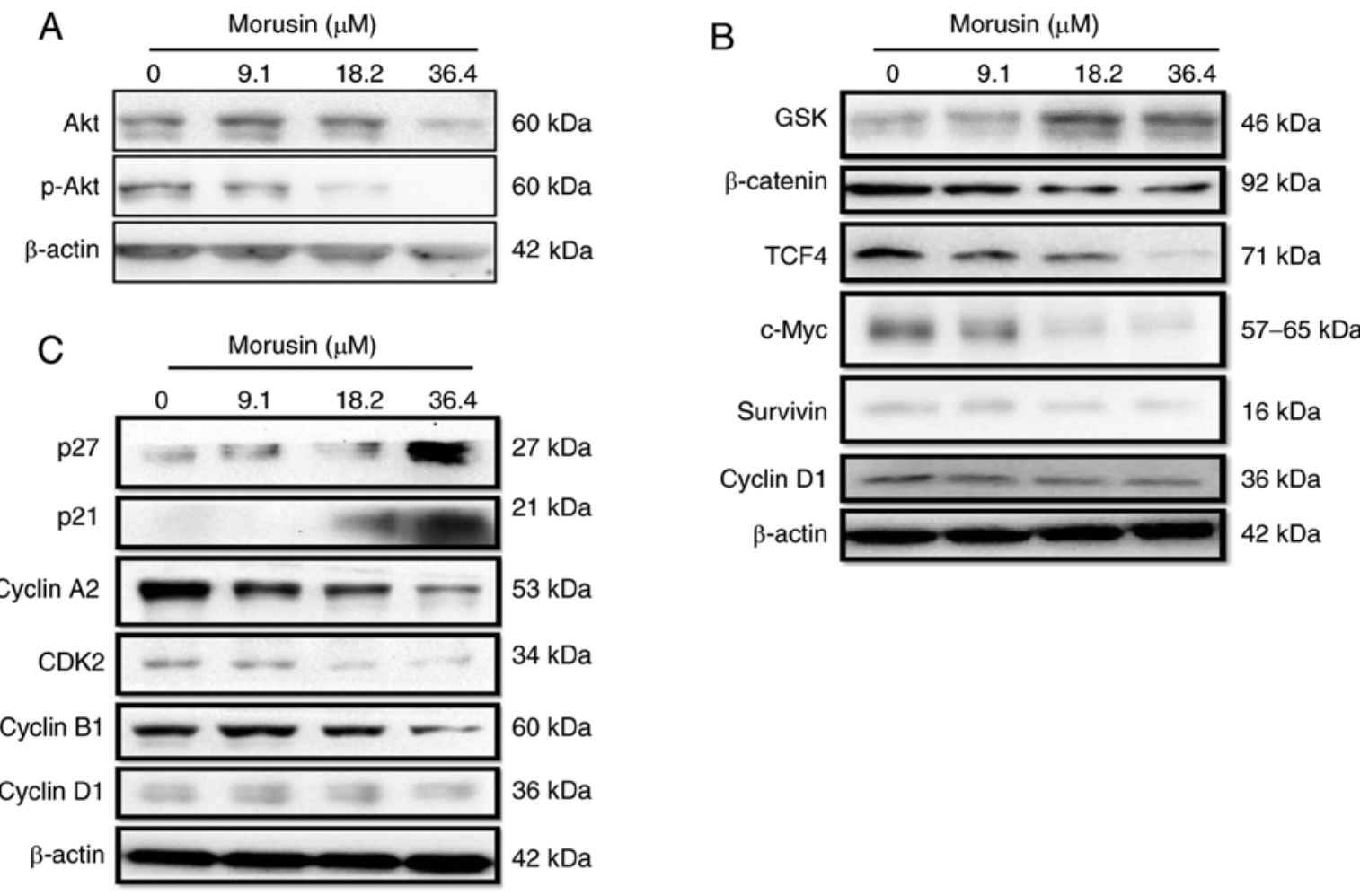

Figure 6. Effect of morusin on the expression of Akt and its target proteins in HCT116 sphere cells. (A) Following treatment with morusin (9.1, 18.2 and $36.4 \mu \mathrm{M}$ ) for $24 \mathrm{~h}$, western blot analysis for Akt activity was performed. (B) Morusin-induced inactivation of $\beta$-catenin signaling and its downstream proteins. (C) Effect of morusin on the expression of p21Cip1/WAF1, p27Kip1, and other cell cycle-related proteins.

growth inhibition of HCT116 sphere cells were investigated. Following incubation with $9.1,18.2$ and $36.4 \mu \mathrm{M}$ morusin for $24 \mathrm{~h}$, the activity of Akt/protein kinase B and $\beta$-catenin signaling was detected by western blot analysis. The expression levels of total Akt and phosphorylated Akt at Ser473 are required for Akt activation (22). In the present study, morusin inhibited the expression of total Akt at the higher concentration $(36.4 \mu \mathrm{M})$ and suppressed the phosphorylation of Akt in a concentration-dependent manner (Fig. 6A). As shown in Fig. 6B, the morusin-induced inactivation of Akt increased the expression of Gsk-3 $\beta$, which is a common target of the Akt and $\mathrm{Wnt} / \beta$-catenin pathway (23). Activated Gsk-3 $\beta$ decreased the expression of $\beta$-catenin, followed by a reduction in TCF4 expression. Furthermore, morusin suppressed downstream targets of the Wnt/ $\beta$-catenin pathway (c-Myc and survivin) in a concentration-dependent manner, which decreased the expression of cyclin D1 at the higher concentration of morusin $(36.4 \mu \mathrm{M})$.

Morusin modulates the expression of cell cycle-related proteins via the activation of 21 Cip1/WAF1 and p27Kipl. Inactivated Akt can also increase the expression of p21Cip1/WAF1 and p27Kip1 (24). Morusin upregulated the expression of p21Cip1/WAF1 and p27Kip1 via the inactivation of Akt and then suppressed a number of cell cycle-related proteins, including cyclin A and CDK2 (Fig. 6C), that participate in the progression through the $\mathrm{S}$ and $\mathrm{G} 2$ phases cooperatively (25). The reduced cyclin A-CDK2 complex expression induced cell cycle arrest at the $\mathrm{S}$ phase, which was consistent with the results of the cell cycle distribution assay (Fig. 4).

\section{Discussion}

Colorectal cancer causes approximately 694,000 deaths per year worldwide (1). Despite recent advancements being made in therapies, the response rate to current systemic therapies is $\sim 50 \%$, resistance develops in nearly all patients (26). Although the mechanisms invovled remain unclear, chemoresistant colorectal CSCs are an important cause. Conventional antitumor therapies that can eliminate the bulk of tumor cells, cannot target CSCs that may lead to a reduction of the tumor mass, but not the regression of the tumor (27). Natural products are proposed as candidates for targeting CSCs $(28,29)$. The present study demonstrated that morusin exerts antitumor effects on CCSCs.

In the present study, spheroid formation was induced in a serum-free and non-adhesive floating culture system (SFM) enriched with CCSCs (19), as it has been demonstrated that sphere cells are enriched in CCSCs $(20,21)$. Compared with parental HCT116 cells, sphere cells exhibited an increased proliferative capacity and a higher expression of pluripotent transcriptional factors (Oct4, Sox 2 and Nanog), core components of the pluripotency regulation network that also maintain the stem-like properties of CSCs $(20,30,31)$ and are considered to be colorectal CSCs markers (32). It was observed that morusin not only inhibited the growth of colorectal sphere cells, but also suppressed the initiation of colorectal cancer spheroid formation. Similarly, morusin decreased the expression of the stemness markers, Oct4 and Nanog. Subsequently, further experiments were performed to examine the mechanisms responsible for the effects of morusin on HCT116 sphere cells. 


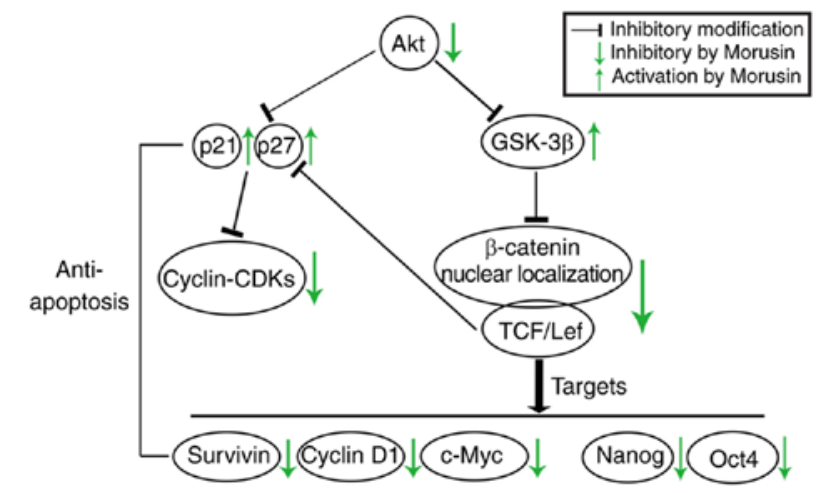

Figure 7. Model depicting the role of Morusin in Akt/ $\beta$-catenin and Akt/p21Cip1/WAF1 p27Kip1 pathway of CCSCs. CCSCs, colorectal cancer stem cells.

The potential molecular mechanisms of the effects of morusin on CCSCs were demonstrated in the present study. First, activated Akt downregulates the activity of GSK-3 $\beta$ (33), which is also a signaling target of the canonical Wnt/ $\beta$-catenin pathway. It is recognized that the Wnt//-catenin pathway carries activating mutations in virtually all colon cancers (34) and plays an important role in CCSCs (2). The constitutive activation of the Wnt/ $\beta$-catenin pathway triggers the tumor-initiating potential $(35,36)$ and maintains the growth of CSCs (tumorspheres in vitro) (20). The Akt-mediated inactivation of GSK-3 $\beta$ results in the stabilization and accumulation of $\beta$-catenin in the cytoplasm, followed by the nuclear translocation of $\beta$-catenin, which leads to the activation of the canonical Wnt pathway. In the cell nucleus, $\beta$-catenin binds to members of the T-cell factor (TCF)/lymphoid enhancer factor (LEF) family to modulate the expression of target genes. In addition, Nanog and Oct4 are also downstream targets of $\beta$-catenin pathway $(37,38)$, which may partly explain why $\mathrm{Wnt} / \beta$-catenin signaling plays a role in sustaining stemness.

In the present study, the expression levels of total Akt and phosphorylated Akt at Ser473, which is required for Akt activation (22), were assayed by western blot analysis. The morusin-induced inactivation of Akt significantly increased the expression of GSK and decreased the activity of $\beta$-catenin. In turn, the expression of TCF 4 expression, which is a critical factor in response to $\beta$-catenin (39), was decreased, and the $\beta$-catenin/TCF4 complex is an important effector of $\mathrm{Wnt} / \beta$-catenin signaling. Morusin reduced the expression of the downstream proteins, c-Myc [a known promoter of cell proliferation and growth (40), survivin [a member of the inhibitor of apoptosis protein (IAP) family that inhibits caspases and blocks cell death (41), and cyclin D1 (which facilitates cell-cycle progression through the G1 phase (42). In particular, Nanog and Oct4 are directly regulated by the $\beta$-catenin/TCF complex $(37,38)$. Nanog not only is a CSC marker, but also promotes cell proliferation $(43,44)$; the results indicated that morusin downregulated Oct4 and Nanog expression via the suppression of the $\beta$-catenin/TCF4 complex. Taken together, the results demonstrated that Morusin inhibited the growth of HCT116 sphere cells and decreased stemness marker expression via the Akt/GSK/ $\beta$-catenin pathway.
According to the second pathway shown in Fig. 7, activated Akt directly or indirectly decreased the expression of p21Cip1/WAF1 and p27Kip1 $(45,46)$, which belong to the CDK interacting protein/kinase inhibitory protein (CIP/KIP) family, a CDK inhibitor that can halt the cell cycle by interacting with a variety of cyclin-CDK complexes (47). The morusin-induced inactivation of Akt attenuated its suppression of the growth inhibitory activity of p21 and p27, which led to a reduction in cyclin A-CDK2 complex formation, which is required for cell cycle progression through the $\mathrm{S}$ and G2 phases (25). Furthermore, the morusin-induced reduction in TCF4 expression can also contribute to the increase in p27 expression cooperatively (48). As a result of the inactivity of cyclin A-CDK2, morusin induced cell cycle arrest at the $\mathrm{S}$ phase (Fig. 4), and the EdU incorporation assay further demonstrated that the proliferative ability was inhibited (Fig. 2C and D). According to the above, morusin blocked cell cycle progression in CCSCs via the Akt/p21Cip1/WAF1 p27Kip1 pathway to inhibit cell proliferation.

It has been reported that morusin induced cancer cell apoptosis $(10,14)$. The results of the present study were consistent with those of these other studies. It was found that morusin promoted the apoptosis of HCT116 sphere cells in a concentration-dependent manner. In addition, it was found that morusin was able to increase the expression of p21Cip1/WAF1 and p27Kip1, resulting in inducing cell cycle arrest. Although the mechanism involved is unclear, it was hypothesized that it was associated with the upregulation of p21Cip1/WAF1 expression (49).

In conclusion, the present study demonstrated that Morusin inhibited the growth of colorectal cancer sphere cells, which were enriched with CCSCs. Morusin induced the inactivation of Akt followed by the suppression of $\beta$-catenin signaling, which resulted in a reduction in stemness marker expression and cell growth inhibition. Morusin also increased the expression of p21Cip1/WAF1 and p27Kip1 and induced cell cycle arrest. Morusin may thus be considered a novel antitumor agent targeting CSCs.

\section{Acknowledgements}

Not applicable.

\section{Funding}

The present study was supported by a grant from the National Nature Science Foundation Project (no. 81703967).

\section{Availability of data and materials}

All data generated or analyzed during this study are included in this published article or are available from the corresponding author on reasonable request.

\section{Authors' contributions}

YZ performed the experiments and wrote the manuscript. XL assisted in performing the experiments and processed all the figures. MY designed of the study, provided funding support and revised the manuscript. All authors read and approved the final manuscript. 


\section{Ethics approval and consent to participate}

Not applicable.

\section{Patient consent for publication}

Not applicable.

\section{Competing interests}

The authors declare that they have no competing interests.

\section{References}

1. Siegel RL, Miller KD, Fedewa SA, Ahnen DJ, Meester RGS Barzi A and Jemal A: Colorectal cancer statistics, 2017. CA Cancer J Clin 67: 177-193, 2017.

2. Roy S and Majumdar AP: Signaling in colon cancer stem cells. J Mol Signal 7: 11, 2012.

3. Markowitz SD and Bertagnolli MM: Molecular origins of cancer: Molecular basis of colorectal cancer. N Engl J Med 361 2449-2460, 2009

4. Clarke MF, Dick JE, Dirks PB, Eaves CJ, Jamieson CH, Jones DL, Visvader J, Weissman IL and Wahl GM: Cancer stem cells-perspectives on current status and future directions. Cancer Res 166: 9339-9344, 2006.

5. Ponti D, Zaffaroni N, Capelli C and Daidone MG: Breast cancer stem cells: An overview. Eur J Cancer 42: 1219-1224, 2006

6. Fan CW, Chen T, Shang YN, Gu YZ, Zhang SL, Lu R, OuYang SR, Zhou X, Li Y, Meng WT, et al: Cancer-initiating cells derived from human rectal adenocarcinoma tissues carry mesenchymal phenotypes and resist drug therapies. Cell Death Dis 4: e828, 2013.

7. Zhang L, Jiao M, Li L, Wu D, Wu K, Li X, Zhu G, Dang Q, Wang X, Hsieh JT and He D: Tumorspheres derived from prostate cancer cells possess chemoresistant and cancer stem cell properties. J Cancer Res Clin Oncol 138: 675-686, 2012.

8. Puglisi MA, Barba M, Corbi M, Errico MF, Giorda E, Saulnier N, Boninsegna A, Piscaglia AC, Carsetti R, Cittadini A, et al: Identification of Endothelin-1 and NR4A2 as CD133-regulated genes in colon cancer cells. J Pathol 225: 305-314, 2011.

9. Jones RJ, Matsui WH and Smith BD: Cancer stem cells: Are we missing the target? J Natl Cancer Inst 96: 583-585, 2004

10. Wang L, Guo H, Yang L, Dong L, Lin C, Zhang J, Lin P and Wang X: Morusin inhibits human cervical cancer stem cell growth and migration through attenuation of NF- $\mathrm{BB}$ activity and apoptosis induction. Mol Cell Biochem 379: 7-18, 2013.

11. Fu Y, Chang H, Peng X, Bai Q, Yi L, Zhou Y, Zhu J and Mi M: Resveratrol inhibits breast cancer stem-like cells and induces autophagy via suppressing Wnt/ $\beta$-catenin signaling pathway. PLoS One 9: e102535, 2014.

12. Li Y and Zhang T: Targeting cancer stem cells by curcumin and clinical applications. Cancer Lett 346: 197-205, 2014.

13. Lee YJ, Chang CF, Lin CW, Huang YC, Hu CC, Tsheng YM and Tseng TH: The first total synthesis of morusin and himanimide D as arachidonate 5-lipoxygenase inhibitor in automated docking. Biophys J 96 (Suppl 1): 86A, 2009.

14. Lee JC, Won SJ, Chao CL, Wu FL, Liu HS, Ling P, Lin CN and Su CL: Morusin induces apoptosis and suppresses NF- $\kappa B$ activity in human colorectal cancer HT-29 cells. Biochem Biophys Res Commun 372: 236-242, 2008.

15. Wan LZ, Ma B and Zhang YQ: Preparation of morusin from Ramulus mori and its effects on mice with transplanted $\mathrm{H} 22$ hepatocarcinoma. Biofactors 40: 636-645, 2014.

16. Ma JP, Qiao X, Pan S, Shen H, Zhu GF and Hou AJ: New isoprenylated flavonoids and cytotoxic constituents from Artocarpus tonkinensis. J Asian Nat Prod Res 12: 586-592, 2010.

17. Lee HJ, Lyu da H, Koo U, Nam KW, Hong SS, Kim KO, Kim KH, Lee D and Mar W: Protection of prenylated flavonoids from Mori Cortex Radicis (Moraceae) against nitric oxide-induced cell death in neuroblastoma SH-SY5Y cells. Arch Pharm Res 35: 163-170, 2012

18. Schmittgen TD and Livak KJ: Analyzing real-time PCR data by the comparative C(T) method. Nat Protoc 3: 1101-1108, 2008.
19. Vermeulen L, De Sousa E Melo F, van der Heijden M, Cameron K, de Jong JH, Borovski T, Tuynman JB, Todaro M, Merz $\mathrm{C}$, Rodermond $\mathrm{H}$, et al: Wnt activity defines colon cancer stem cells and is regulated by the microenvironment. Nat Cell Biol 12: 468-476, 2010.

20. Kanwar SS, Yu Y, Nautiyal J, Patel BB and Majumdar AP: The Wnt/beta-catenin pathway regulates growth and maintenance of colonospheres. Mol Cancer 9: 212, 2010.

21. Li YF, Xiao B, Tu SF, Wang YY and Zhang XL: Cultivation and identification of colon cancer stem cell-derived spheres from the Colo205 cell line. Braz J Med Biol Res 45: 197-204, 2012.

22. Ohigashi T, Mizuno R, Nakashima J, Marumo K and Murai M: Inhibition of Wnt signaling downregulates Akt activity and induces chemosensitivity in PTEN-mutated prostate cancer cells. Prostate 62: 61-68, 2005.

23. Sutton LP and Rushlow WJ: Regulation of Akt and Wnt signaling by the group II metabotropic glutamate receptor antagonist LY341495 and agonist LY379268. J Neurochem 117: 973-983, 2011.

24. Jain MV, Jangamreddy JR, Grabarek J, Schweizer F, Klonisch T, Cieślar-Pobuda A and Łos MJ: Nuclear localized Akt enhances breast cancer stem-like cells through counter-regulation of p21(Waf1/Cip1) and p27(kip1). Cell Cycle 14: 2109-2120, 2015.

25. Chowdhury R, Chatterjee R, Giri AK, Mandal C and Chaudhuri K: Arsenic-induced cell proliferation is associated with enhanced ROS generation, Erk signaling and Cyclin A expression. Toxicol Lett 198: 263-271, 2010.

26. Dallas NA, Xia L, Fan F, Gray MJ, Gaur P, van Buren G II, Samuel S, Kim MP, Lim SJ and Ellis LM: Chemoresistant colorectal cancer cells, the cancer stem cell phenotype, and increased sensitivity to insulin-like growth factor-I receptor inhibition. Cancer Res 69: 1951-1957, 2009.

27. Paldino E, Tesori V, Casalbore P, Gasbarrini A and Puglisi MA: Tumor initiating cells and chemoresistance: Which is the best strategy to target colon cancer stem cells? Biomed Res Int 2014: 859871, 2014

28. Burnett J, Newman B and Sun D: Targeting cancer stem cells with natural products. Curr Drug Targets 13: 1054-1064, 2012.

29. Bao B, Li Y, Ahmad A, Azmi AS, Bao G, Ali S, Banerjee S, Kong D and Sarkar FH: Targeting CSC-related miRNAs for cancer therapy by natural agents. Curr Drug Targets 13: 1858-1868, 2012.

30. Levings PP, McGarry SV, Currie TP, Nickerson DM, McClellan S, Ghivizzani SC, Steindler DA and Gibbs CP: Expression of an exogenous human Oct-4 promoter identifies tumor-initiating cells in osteosarcoma. Cancer Res 69: 5648-5655, 2009.

31. Shan J, Shen J, Liu L, Xia F, Xu C, Duan G, Xu Y, Ma Q, Yang Z, Zhang $Q$, et al: Nanog regulates self-renewal of cancer stem cells through the insulin-like growth factor pathway in human hepatocellular carcinoma. Hepatology 56: 1004-1014, 2012.

32. Merlos-Suárez A, Barriga FM, Jung P, Iglesias M, Céspedes MV, Rossell D, Sevillano M, Hernando-Momblona X, da Silva-Diz V, Muñoz $\mathrm{P}$, et al: The intestinal stem cell signature identifies colorectal cancer stem cells and predicts disease relapse. Cell Stem Cell 8: 511-524, 2011.

33. Chen RH, Ding WV and McCormick F: Wnt signaling to beta-catenin involves two interactive components glycogen synthase kinase-3beta inhibition and activation of protein kinase C. J Biol Chem 275: 17894-17899, 2000.

34. Prasetyanti PR, Zimberlin CD, Bots M, Vermeulen L, Melo Fde S and Medema JP: Regulation of stem cell self-renewal and differentiation by Wnt and Notch are conserved throughout the adenoma-carcinoma sequence in the colon. Mol Cancer 12: 126 , 2013.

35. Shenoy AK, Fisher RC, Butterworth EA, Pi L, Chang LJ, Appelman HD, Chang M, Scott EW and Huang EH: Transition from colitis to cancer: High Wnt activity sustains the tumor-initiating potential of colon cancer stem cell precursors. Cancer Res 72: 5091-5100, 2012.

36. Li Y, Welm B, Podsypanina K, Huang S, Chamorro M, Zhang X, Rowlands T, Egeblad M, Cowin P, Werb Z, et al: Evidence that transgenes encoding components of the Wnt signaling pathway preferentially induce mammary cancers from progenitor cells. Proc Natl Acad Sci USA 100: 15853-15858, 2003.

37. Ibrahim EE, Babaei-Jadidi R, Saadeddin A, Spencer-Dene B, Hossaini S, Abuzinadah M, Li N, Fadhil W, Ilyas M, Bonnet D and Nateri AS: Embryonic NANOG activity defines colorectal cancer stem cells and modulates through AP1-and TCF-dependent mechanisms. Stem cells 30: 2076-2087, 2012.

38. Li J, Li J and Chen B: Oct4 was a novel target of Wnt signaling pathway. Mol Cell Biochem 362: 233-240, 2012. 
39. Zhang Y, Liu C, Duan X, Ren F, Li S, Jin Z, Wang Y, Feng Y, Liu Z and Chang Z: CREPT/RPRD1B, a recently identified novel protein highly expressed in tumors, enhances the $\beta$-catenin-TCF4 transcriptional activity in response to Wnt signaling. J Biol Chem 289: 22589-22599, 2014.

40. Dang CV: MYC on the path to cancer. Cell 149: 22-35, 2012.

41. Kelly RJ, Lopez-Chavez A, Citrin D, Janik JE and Morris JC: Impacting tumor cell-fate by targeting the inhibitor of apoptosis protein survivin. Mol Cancer 10: 35, 2011.

42. Diaz-Moralli S, Tarrado-Castellarnau M, Miranda A and Cascante M: Targeting cell cycle regulation in cancer therapy. Pharmacol Ther 138: 255-271, 2013.

43. Wang ML, Chiou SH and Wu CW: Targeting cancer stem cells: Emerging role of Nanog transcription factor. Onco Targets Ther 6: 1207-1220, 2013.

44. Choi SC, Choi JH, Park CY, Ahn CM, Hong SJ and Lim DS: Nanog regulates molecules involved in stemness and cell cycle-signaling pathway for maintenance of pluripotency of P19 embryonal carcinoma stem cells. J Cell Physiol 227: 3678-3692, 2012.

45. Zhou BP, Liao Y, Xia W, Spohn B, Lee MH and Hung MC: Cytoplasmic localization of p21 Cip1/WAF1 by Akt-induced phosphorylation in HER-2/neu-overexpressing cells. Nature Cell Biol 3: 245-252, 2001.
46. Engelman JA, Luo J and Cantley LC: The evolution of phosphatidylinositol 3-kinases as regulators of growth and metabolism. Nat Rev Genet 7: 606-619, 2006

47. Zheng X, Wang Y, Liu B, Liu C, Liu D, Zhu J, Yang C, Yan J, Liao X, Meng X and Yang H: Bmi-1-shRNA inhibits the proliferation of lung adenocarcinoma cells by blocking the G1/S phase through decreasing cyclin D1 and increasing p21/p27 levels. Nucleic Acid Ther 24: 210-216, 2014.

48. Xie J, Xiang DB, Wang H, Zhao C, Chen J, Xiong F, Li TY and Wang XL: Inhibition of Tcf-4 induces apoptosis and enhances chemosensitivity of colon cancer cells. PLoS One 7: e45617, 2012.

49. Asada M, Yamada T, Ichijo H, Delia D, Miyazono K, Fukumuro K and Mizutani S: Apoptosis inhibitory activity of cytoplasmic p21(Cip1/WAF1) in monocytic differentiation. EMBO J 18: 1223-1234, 1999.

This work is licensed under a Creative Commons Attribution-NonCommercial-NoDerivatives 4.0 International (CC BY-NC-ND 4.0) License. 